AN. MED. INTERNA (Madrid) Vol. 18, N. $^{\circ}$, pp. $376-378,200$

\title{
Diabetes insípida central como presentación clínica de un adenocarcinoma bronquial
}

\author{
M. BORONAT, D. MARRERO, A. CARRILLO, F. LARROCHE, A. OJEDA, \\ F.J. NÓVOA
}

Sección de Endocrinología y Nutrición. Hospital Insular. Las Palmas de Gran Canaria

CENTRAL DIABETES INSIPIDUS AS CLINICAL PRESENTATION OF A BRONCHOGENIC ADENOCARCINOMA

\begin{abstract}
RESUMEN
Los tumores metastásicos de la glándula hipofisaria son poco comunes. En su mayoría son lesiones silentes descubiertas accidentalmente en la autopsia. La aparición de metástasis sintomáticas es, en cambio, excepcional. Describimos aquí las hallazgos clínicos y radiológicos de una mujer de 45 años con un adenocarcinoma bronquial metastásico que se presentó con diabetes insípida y deshidratación hipernatrémica. No existía antecedente conocido de malignidad y la metástasis hipofisaria fue la primera manifestación de la enfermedad. Se revisa la presentación clínica, diagnóstico y enfoque terapéutico de los pacientes con metastasis hipofisarias.
\end{abstract}

PALABRAS CLAVE: Metástasis. Diabetes insípida. Carcinoma bronquial.

\begin{abstract}
Metastatic tumors of the pituitary gland are uncommon. The majo rity of them are silent lesions incidentally descovered at autopsy. In con trast, the occurrence of symptomatic metastases is exceptional. Here we report the clinical and radiological findings of a 45 year-old woman with a metastatic lung adenocarcinoma who presented with diabetes insipidus and hypernatremic dehydration. There was no previous history of malig nancy, and the pituitary metastases were responsable for the first mani festation of the disease. Clinical presentation, diagnosis and therapeutic management of patients with pituitary metastases are reviewed.
\end{abstract}

KEY WORDS: Pituitary metastases. Diabetes insipidus. Lung carcino ma.

Boronat M, Marrero D, Carrillo A, Larroche F, Ojeda A, Nóvoa FJ. Diabetes insípida central como presentación clínica de un adenocarcino ma bronquial. An Med Interna (Madrid) 2001; 18: 376-378.

\section{INTRODUCCIÓN}

Los tumores hipofisarios representan el $10 \%$ de las neoplasias intracraneales clínicamente significativas. Si bien en su gran mayoría son adenomas de la hipófisis anterior, otras lesiones tumorales pueden asentar en la región hipotálamo-hipofisaria. Entre ellas, aunque raras, hay que considerar la existencia de metástasis de otros tumores, depositadas en la región selar a través de diseminación hematógena. Lo habitual es que estas metástasis se desarrollen en fases avanzadas de la enfermedad, en cuyo caso no lleguen a originar manifestaciones clínicas o lo hagan cuando el diagnóstico del cáncer primitivo ya es conocido, habitualmente con invasión metastásica de otros puntos de la economía. Presentamos aquí un caso de adenocarcinoma bronquial que debutó, en una paciente sin antecedentes conocidos de malignidad, en forma de diabetes insípida central, como consecuencia de una metástasis hipofisaria.

\section{CASO APORTADO}

Mujer de 45 años, fumadora de 40 cigarrillos/día y sin antecedentes patológicos conocidos, remitida al Servicio de Urgencias en situación estuporosa tras progresivo deterioro del nivel de conciencia en el curso de 48 horas. La familia de la paciente refería el desarrollo previo de un síndrome constitucional, con pérdida de $10 \mathrm{~kg}$ de peso en los últimos 3 meses, así como poliuria, polidipsia (hasta 10 litros de agua al día) y avidez al consumo de bebidas frías en las semanas previas a la consulta.

En el examen físico destacaba una tensión arterial de 90/70 mmHg y signos evidentes de una importante deshidratación cutaneomucosa. Se palpaban dos adenopatías de consistencia dura en fosa supraclavicular derecha y región retroauricular del mismo lado. El resto de la exploración era normal.

Los exámenes complementarios practicados en Urgencias revelaron una concentración plasmática de $\mathrm{Na}+$ de $163 \mathrm{mmol} / \mathrm{L}$, con una osmolaridad calculada de $367 \mathrm{mosm} / \mathrm{L}$. Exceptuando una discreta elevación de las cifras iniciales de urea y creatinina, otros estudios

Trabajo aceptado: 29 de Noviembre de 1999

Correspondencia: Mauro Boronat. Sección de Endocrinología y Nutrición. Hospital Insular. Avda. Marítima del Sur, s/n. 35016 Las Palmas de Gran Canaria 
analíticos realizados en ese momento y durante los días subsiguientes fueron normales, incluyendo hemograma, estudio de coagulación, glucemia, bioquímica hepática y determinaciones plasmáticas de TSH, T4 libre, ACTH, cortisol, FSH, LH, estradiol y prolactina.

En la radiografía simple de tórax se apreciaba la existencia de numerosos nódulos pulmonares, dos de ellos de mayor tamaño y contornos irregulares, situados en el lóbulo superior del pulmón derecho. Se realizó una mamografía, que no detectó imágenes patológicas, y una tomografía axial computarizada (TAC) toracoabdominal, que confirmó la presencia de los nódulos pulmonares mayores, de 3 y $4 \mathrm{~cm}$ de diámetro respectivamente, así como de adenopatías mediastínicas y múltiples nódulos de hasta $1 \mathrm{~cm}$ distribuidos por ambos campos pulmonares. El estudio de la región abdominopélvica fue normal.

Una TAC de cráneo, incluyendo cortes coronales para visualizar la silla turca, fracasó en detectar lesiones ocupantes de espacio. Sin embargo, la resonancia magnética nuclear de la región hipofisaria permitió detectar la existencia de una metástasis que ocupaba de manera difusa la región selar, en forma de una masa hiperintensa y homogénea, de $1,5 \mathrm{~cm}$ de tamaño (Fig. 1). La señal hiperintensa que habitualmente produce la neurohipófisis en las imágenes obtenidas en secuencia T1 estaba ausente.

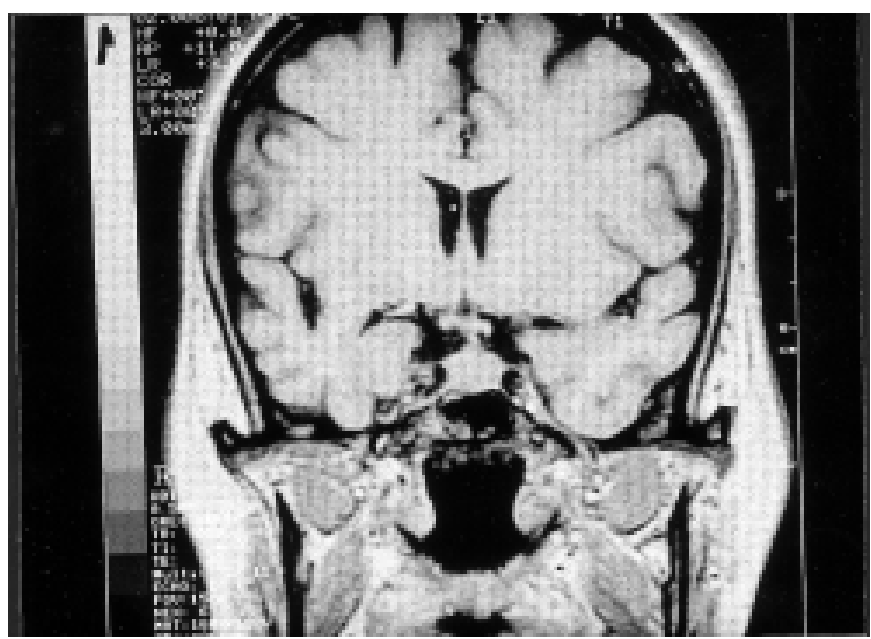

Fig. 1. Resonancia magnética nuclear hipofisaria, corte coronal en T1. M asa hipofisaria que ocupa globalmente el contenido de la silla turca y que parece infiltrar el tallo hipofisario, desplazado hacia la izquierda y visiblemente engrosado.

La biopsia de la adenopatía supraclavicular derecha fue diagnos ticada como metástasis de adenocarcinoma. Debido al mal pronóstico del caso, la familia desestimó ninguna otra medida diagnóstica o terapéutica más allá del tratamiento paliativo. El diagnóstico de presunción fue de adenocarcinoma bronquial con metástasis pulmonares, ganglionares y en región hipotálamo-hipofisaria.

En un primer momento la paciente recibió la administración de fluídos hipotónicos por vía intravenosa hasta corregirse la deplección de volumen y la hipernatremia, con lo cual desaparecieron las alteraciones cognitivas. Posteriormente se inició tratamiento con desmopresina, por vía intranasal (10 $\mu \mathrm{g} / 12$ horas), e ingesta libre de agua, manteniéndose con ello un normal balance hidroelectrolítico. La paciente falleció 45 días después del diagnóstico.

\section{DISCUSIÓN}

La región hipotálamo-hipofisaria es una localización relativamente rara para la implantación metastásica de neoplasias sistémicas. Con mayor frecuencia, y por este orden, las metástasis proceden de carcinomas de mama, pulmón, tubo digestivo, próstata y tumores de origen hematológico (1). Generalmente pasan clínicamente desapercibidas, constituyendo un hallazgo accidental postmortem. Así, por ejemplo, en una revisión de 88 necropsias en las que se documentó su presencia, sólo 6 casos habían presentado sintomatología derivada de invasión metastásica de la hipófisis (2).

Curiosamente, sin embargo, y tal y como sucedió en el caso que presentamos, cuando se expresan clínicamente, las metástasis hipofisarias pueden ser el motivo del diagnóstico del tumor primitivo en algunos casos $(3,4)$.

Su manifestación clínica más frecuente es la diabetes insípida. De hecho, la aparición de ésta obliga a considerar siempre la posibilidad de una metástasis hipofisaria, ya que las metástasis representan hasta el $14 \%$ de los casos de diabetes insípida de cualquier causa (5). Pueden existir, además, déficits visuales campimétricos, originados por la compresión ejercida sobre el quiasma óptico, cefalea, oftalmoplejía o grados variables de hipopituitarismo. Este último es poco habitual, ya que la afectación de la adenohipófisis es mucho menos frecuente que la de la neurohipófisis (2).

En el caso que presentamos, la diabetes insípida central completa era evidente dentro del contexto clínico. La mala situación de la paciente explica el desarrollo de una deshidratación hipernatrémica, que no es habitual en este proceso si el enfermo tiene libre acceso a la ingesta de agua. Cuando la deficiencia de hormona antidiurética es sólo parcial, la poliuria es moderada (entre 3 y 6 litros/día) y puede ser necesario recurrir a un test de deshidratación para confirmar el diagnóstico y determinar si el origen de la diabetes insípida es central o nefrogénico (6).

La resonancia magnética nuclear puede contribuir al diagnóstico cuando se observa la existencia de una masa en la región hipotalamo-hipofisaria en un paciente oncológico. La TAC, incluso cuando se emplean cortes coronales para visualizar la silla turca, tiene una sensibilidad mucho menor y puede dar lugar a falsos negativos, como queda ilustrado con el presente caso. La iconografía aquí aportada representa la típica imagen de una metástasis hipofisaria, en forma de una masa hiperintensa que ocupa difusamente toda la silla turca y el tallo hipofisario. Al igual que en un alto porcentaje de casos de diabetes insípida, cualquiera que sea su etiología, estaba ausente la señal hiperintensa generalmente originada por la neurohipófisis en las imágenes en T1 (7). El diagnóstico por imagen aisladamente, no obstante, difícilmente permite distinguir entre un adenoma hipofisario y una lesión metastásica. De hecho, cuando se presentan sin diabetes insípida y se desconoce la existencia del tumor primario, las metástasis son a menudo confundidas con adenomas hipofisarios no secretores (3).

El tratamiento debe ir dirigido al tumor primitivo y, cuando exista, a la corrección de la diabetes insípida. En aquellos casos que presenten déficits visuales campimétricos o parálisis oculomotora, puede ser necesario efectuar una descompresión quirúrgica por vía transesfenoidal, para liberar las vías ópticas o los pares craneales afectados. Tras la cirugía es práctica habitual aplicar radioterapia hipofisaria mediante acelerador lineal. La presencia de una metástasis hipofisaria, en cualquier caso, implica un pronóstico ominoso, y la supervivencia media a partir de su diagnóstico se reduce a los seis meses (4). 


\section{Bibliografía}

1. McCormick PC, Post KD, Kandji AD, Hayes AP. Metastatic carcinoma to the pituitary gland. Br J Neurosurg 1989; 3:71-79.

2. Teers RJ, Silverman EM. Clinicopathologic review of 88 cases of carcinoma metastatic to the pituitary gland. Cancer $1975 ; 36: 216-220$.

3. Branch CL, Laws ER. Metastatic tumors of the sella turcica masquerading as primary pituitary tumors. J Clin Endocrinol Metab 1987; 65: 469474.

4. Morita A, Meyer FB, Laws ER Jr. Symptomatic pituitary metastases. J Neurosurg 1998; 89: 69-73.
5. Kimmel DW, O'Neill BP. Systemic cancer presenting as diabetes insipidus. Clinical and radiographic features of 11 patients with a review of metastatic-induced diabetes insipidus. Cancer 1983; 52: 2355-2358.

6. Miller M, Dalakos T, Moses AM. Recognition of partial defects in antidiuretic hormone secretion. Ann Intern Med 1970; 73: 721-729.

7. Fusisawa I, Kazumasa N, Asato R, et al. Posterior lobe of the pituitary in diabetes insipidus: MR findings. J Comput Assist Tomogr 1987; 11: 221225 . 